\title{
Roles of Self-Efficacy and Learning Motivation in Learning
}

\author{
Sifan Cheng* \\ University of York, York, England \\ *Corresponding author: 943114851@qq.com
}

Keywords: Self-efficacy, Learning motivation, Learning, Mechanism.

\begin{abstract}
This study explained the effects of self-efficacy and learning motivation on students' learning and the influencing mechanism. Specifically, self-efficacy can affect students' learning through their emotional state and their choice of learning tasks' difficulty. Learning motivation is also a crucial factor in learning, and different types of learning motivation play different roles in the learning process. The effects of intrinsic motivation and extrinsic motivation are discussed in this paper. Correspondingly, several ways to foster learning motivation and self-efficacy are analysed and provided as well. It is expected that this article can help educators and researchers to further understand the roles of self-efficacy and learning motivation in students' learning, and also help them to adopt proper measures to improve students' academic performance.
\end{abstract}

\section{Introduction}

As the main indicators of psychological regulation, and sources of rewards and satisfaction, as well as the performance in the academic field, academic success has a critical influence on the lives of adolescent students $[1,2]$. Therefore, it is meaningful to focus on the influencing factors that can enable teenagers to achieve academic success in school [3,4]. Previous studies suggested that learning motivation and self-efficacy played important roles in promoting their performance at school [5]. Specifically, learning motivation enables students to learn effectively [6-8]. Also, self-efficacy can be the most critical factor in motivating students' learning. In this paper, the effects of self-efficacy and learning motivation on students' learning behaviour, and others are explained. Besides, several ways to foster learning motivation and self-efficacy are also discussed. Finally, the article summarised the above and gave a conclusion.

\section{The Roles of Self-efficacy in Learning}

Recent studies confirm that self-efficacy can be quite an essential factor in regulating the learning process of a person [9]. Self-efficacy refers to the ability to achieve a given goal and the process of managing the jobs [10]. It reflects the skills of a person to perform in a specific situation and affects the choice of the task, effort, persistence, and achievement.

Self-efficacy may affect students' learning through their emotional state. Previous studies found that the student's sense of self-efficacy has influences on their emotional state of anxiety and depression in the course of learning [11]. For example, Bandura has pointed out that a low level of self-efficacy is associated with the individual's feelings of depression and anxiety. On the contrary, students with a high sense of self-efficacy are good at dealing with all kinds of life events, and will try to overcome difficulties even if they feel challenging, so they are not prone to anxiety. In addition, the stressed students can withstand in the face of threats, difficulties, and other situations, depending on their belief in their problem-solving capabilities. Students who have doubted their ability tend to underestimate their ability to cope [12]. They experience intense stress and anxiety, as they try to exaggerate the difficulties of their mission. Even worse, these types of students, who adopt various protective or defensive practices to passively deal with all kinds of difficulties they might encounter in learning, will inevitably have a negative impact on their actual behavioural implementation processes. However, students who believe that they can effectively control the difficulties of learning do not have to be afraid of learning tasks. Thus, the influence of students' self-efficacy on learning 
determines their thinking and emotion, which affects their daily learning as well [12].

Moreover, self-efficacy can also affect students' learning through their choice of difficult or easy learning tasks [13]. Generally, homework assignments are usually layered, and they include three layers: the basic knowledge layer, the depth of understanding, and the extension layer. Students can make choices based on their abilities, and previous studies found that students' choices usually depend on their sense of self-efficacy. Specifically, students with high self-efficacy levels tend to choose the suitable ability level and challenging learning tasks, while students with a low level of self-efficacy tend to avoid challenging tasks. Some middle-level students may choose the tasks that are easy to solve, due to their low sense of self-efficacy, which is not conducive to their progress. Thus, students' self-efficacy can affect their learning, which is reflected by the different difficulty levels of the learning tasks that they choose.

\section{The Roles of Learning Motivation in Learning}

Learning motivation refers to that learners have a clear learning goal, and they are willing to seek relevant information to achieve them actively and persistently. It is the internal driving force that directly promotes students' learning and plays a significant role in stimulating and guiding students' learning needs. Abundant education and social psychology studies have clearly shown that a student's learning motivation is quite important to drive them to learn better. Learning motivation does not only help students to be highly motivated in learning but also help them to stick to long term learning, to get better outcomes, with higher scores in the ordinary achievement academic tests [14].

It should be noted that learning motivation does not directly affect the cognitive process, but indirectly promote learning effect. Specifically, the motivation for learning is to improve the state of learning by improving the student's willingness to learn and to awaken the student's positive learning mood, which affects the cognitive construction process.

Self-determination theory identifies the motivation types in some situations, such as autonomous (intrinsic), controlled (extrinsic), and lack of motivation (motivational) [15]. Intrinsic motivation can be interpreted as the way to find out issues and problems that they can acquire, reflecting the joy and the satisfaction that they feel from activities. A further definition of the construction of intrinsic motivation is to distinguish between intrinsic perceptual motivation, intrinsic motivation for completion, and intrinsic motivation for experiencing stimuli. People who lack motivation for action may lack confidence and can feel that their actions are futile and worthless. Extrinsic motivation, though it can be controlled by some factors from the external environment, can show the requirements in external areas as responsible for ending the situation. The extrinsic motivation in different areas can contain the regulations from outside, inner side, deterministic regulation, and comprehensive regulation because the degree of self-determination is different.

The type of learning motivation adopted by students can predict the actions and emotions of the students in the learning process, such as emotions, sense of competence, attention, achievement, and persistence in academic activities. Specifically, cognitive drive, as a human need for knowledge, is derived from the innate cognitive curiosity of the individual, namely, the psychological factors related to exploring, operating, and coping with the numerous problems raised by the environment. In the daily learning process, if students can obtain learning results and successful experience through continuous learning, then they are full of expectations for further learning because they can obtain a sense of satisfaction in the whole learning process [16]. Therefore, the cognitive internal drive can reinforce the learning of students who participated in the course material, and can help those who were expected to teach these to the students and aid them to maintain the motivation internally with the better identification of the value rather than just focusing on gaining higher scores[17].

Also, self-improvement belongs to extrinsic motivation, which is the ability that students need to achieve their goals or to win a corresponding status. Self-improvement of the most concentrated expression is that the student works hard, to get good rankings, academic performance in school and use what they have learned to help himself out of the school in his academic career or professional life, and get a higher social status. This demand strengthens as students' ages increase. It is a common phenomenon that students try to improve their academic performance ranking. However, if the 
education workers put too much emphasis on students' ranking, students will have a lot of anxiety and even bad phenomena, such as malicious competition. Besides, it also causes students to study for utilitarian purposes, which is one of the reasons that may lead to mistakes and harm their learning motivation.

\section{The Ways to Foster Self-efficacy and Learning Motivation}

\subsection{The ways to improve students' self-efficacy}

In order to improve students' self-efficacy, it is necessary to take some measures according to the factors that can influence students' self-efficacy. The factors affecting students' self-efficacy mainly include students' enactive attainment, vicarious experience, social persuasion, and attribution style.

First, enactive attainment is an essential factor in determining the self-efficacy of an individual. Successful experience enhances self-efficacy, while failure experience weakens it. Regardless of the size of the target, success in achieving goals is a significant source of self-efficacy. Therefore, when setting goals, students can break down the goals through a series of plans or strategies and then making the goals easier to be achieved. The completion of each small stage of the goals can enhance students' sense of self-efficacy. In the process of goal realisation without high-level planning, failure means the frustration for people with a low sense of self-efficacy or a few people whose sense of self-efficacy is not fully developed, and they may give up trying [8]. More importantly, failure severely weakens the sense of self-efficacy and forms a negative cycle effect.

Second, students' vicarious experience can affect their sense of self-efficacy. When students see someone succeed, their sense of self-efficacy can also increase. On the contrary, when students see someone fail, their sense of self-efficacy diminishes. This influence process is effective when the student's role model is similar to others. While this is not an impact of direct experience, but an exemplary effect of an example, which will be effective when people are not confident about themselves.

Third, social persuasion is also a strong influencing factor, and it is primarily driven by direct inspiration or negative hindrances from others. The negative hindrance to the weakening of self-efficacy is far more significant than the incentive to the enhancement of it. Intense pressure on the study will make students feel pain, fatigue, nausea, and other negative moods. These reactions can significantly change students' sense of self-efficacy, and they are perceived as incompetence by people with low self-efficacy, which will further undermine self-efficacy. People who have self-efficacy to a large degree thought negative emotions were just a common physiological manifestation and did not relate to ability.

Forth, there is an interaction between self-efficacy and people's attribution style. The huge self-efficacy of students can help them to gain success, use it as stable factors to develop their skills, help them make attempts, and control them to stop struggling for lack of goals. This positive attribution can enhance students' self-efficacy. Studies have shown that learning difficulties tend to be negative attributions, and they tend to attribute their learning to uncontrollable factors, such as their ability, their teachers, their luck, and their tasks, and their negative attributions, which can weaken their sense of self-efficacy. Indeed, students' positive attribution approach cannot be overemphasised, or the student can create a feeling of self-efficacy, which can result in the frustration of their self-efficacy. To cultivate positive attributions, teachers need to be aware of the following three requirements: (1) use appropriate emotional expression and verbal evaluation; (2) observe students' learning behaviour and provide appropriate help and guidance for students to complete learning tasks; however, the difference between the difficulty of the task and the situation of the students can be detected; (3) help students set goals [18].

\subsection{The ways to improve students' learning motivation}

Many factors can generate and develop learning motivation. The first factor is the Epistemological belief. Epistemological belief refers to the mode of thinking and learning with respect to knowledge, and it includes an individual's understanding of the structure, stability, and 
certainty of knowledge. It can affect their learning processes, their personal expectations, their work, and their participation in academic tasks. For example, if it is assumed that all knowledge can form an interrelated network, students will learn to connect all new knowledge with previous knowledge in a meaningful way. If a learning task is too challenging, they will think the new information is meaningless to them and not worth learning.

Second, students' learning ability also affects their learning motivation. Specifically, individuals with an entity view of competence believe that competence is fixed, and they tend to set performance goals and try to avoid failure in order to protect themselves. However, if individuals believe that competence can be increased (i.e., hold the view of competence growth), they will tend to set mastery goals and deal with failure constructively. Thus, in practical teaching, teachers can stimulate students' learning motivation through five points. The first is to set specific goals and methods to achieve them. Before the exam, teachers should instruct students on what they should focus on, what to review, and how to arrange their time to review the content of the exam. According to students' situation, teachers set corresponding goals for students, which will make it easy for the students to achieve the goals in the exam, so that the students will have a sense of achievement, which will generate learning motivation. Later, the students will also imitate this method and apply this method to study. The second point is to set learning models for students. According to the learning situation of different students, the teacher can give them advice when communicating with them, and let them find a person who is slightly better than them in various aspects (such as grades) in the class as their examples, so that they can generate an invisible impetus to promote their own learning. When students exceed the model, the teacher can praise them in front of the class, so that they have a sense of achievement, but also not forget to let them find a new learning model, so that they will be able to improve and enhance their learning motivation. The third point is to develop an interest in learning. Teachers can add some interesting course activities to attract students' attention and make them interested in learning. The fourth point is to make use of the transfer of original motivation to generate students' learning needs. It can be used to develop the underachiever learning motivation. The fifth is to pay attention to a student's attribution tendency. Attribution tendency is postnatal, and, therefore, for a teacher, it can be cultivated according to the situation of the students.

\section{Conclusions}

In the learning process, self-efficacy and learning motivation are two critical factors to enhance academic performance. Self-efficacy can be quite crucial in affecting students' learning through their emotional state and their choice of difficult or easy learning tasks. Learning motivation can affect students' learning and is the internal driving force that directly promotes students' learning and plays a role in stimulating and guiding students' learning needs. Different types of learning motivation play a different role in the learning process. The effects of intrinsic motivation and extrinsic motivation are discussed. Correspondingly, the factors which can affect self-efficacy and learning motivation are analysed, and several ways to foster self-efficacy and learning motivation are provided.

\section{References}

[1] Suldo, Shannon M., Emily J. Shaffer, and Kristen N. Riley. "A social-cognitive-behavioral model of academic predictors of adolescents' life satisfaction." School Psychology Quarterly 23.1 (2008): 56.

[2] Wang, Ming-Te, and Rebecca Holcombe. "Adolescents' perceptions of school environment, engagement, and academic achievement in middle school." American educational research journal 47.3 (2010): 633-662.

[3] Bagci, S.C. Does everyone benefit equally from self-efficacy beliefs? The moderating role of perceived social support on motivation. The Journal of Early Adolescence, vol.38, no.2, pp. 204219, 2018. 
[4] Zuffianò, A., Alessandri, G., Gerbino, M., Kanacri, B.P.L., Di Giunta, L., Milioni, M., \& Caprara, G.V. Academic achievement: The unique contribution of self-efficacy beliefs in self-regulated learning beyond intelligence, personality traits, and self-esteem. Learning and Individual Differences, no.23, pp. 158-162, 2013).

[5] Turner, Erlanger A., Megan Chandler, and Robert W. Heffer. "The influence of parenting styles, achievement motivation, and self-efficacy on academic performance in college students." Journal of college student development 50.3 (2009): 337-346.

[6] Joo, Y.J., Lim, K.Y., \& Kim, J. Locus of control, self-efficacy, and task value as predictors of learning outcome in an online university context. Computers \& Education, no.62, pp. 149-158, 2013.

[7] Panadero, E., Jonsson, A., \& Botella, J. Effects of self-assessment on self-regulated learning and self-efficacy: Four meta-analyses. Educational Research Review, no.22, pp. 74-98, 2017.

[8] Katz, I., Eilot, K., \& Nevo, N. "I'll do it later”: Type of motivation, self-efficacy and homework procrastination. Motivation and Emotion, vol.38, no.1, pp. 111-119, 2014.

[9] Ghonsooly, B., \& Ghanizadeh, A. Self-efficacy and self-regulation and their relationship: A study of Iranian EFL teachers. The Language Learning Journal, vol.41, no.1, pp. 68-84, 2013.

[10] Phillips, Jean M., and Stanley M. Gully. "Role of goal orientation, ability, need for achievement, and locus of control in the self-efficacy and goal--setting process." Journal of applied psychology 82.5 (1997): 792.

[11] Cho, M.H., \& Heron, M.L. Self-regulated learning: The role of motivation, emotion, and use of learning strategies in students' learning experiences in a self-paced online mathematics course. Distance Education, vol.36, no.1, pp. 80-99, 2015.

[12] Hen, M., \& Goroshit, M. Academic procrastination, emotional intelligence, academic self-efficacy, and GPA: A comparison between students with and without learning disabilities. Journal of Learning Disabilities, vol.47, no.2, pp. 116-124, 2014.

[13] Honicke, T., \& Broadbent, J. The influence of academic self-efficacy on academic performance: A systematic review. Educational Research Review, no.17, pp. 63-84, 2016.

[14] Lazowski, R.A., \& Hulleman, C.S. Motivation interventions in education: A meta-analytic review. Review of Educational Research, vol.86, no.2, pp. 602-640, 2016.

[15] Ross, M., Perkins, H., \& Bodey, K. Academic motivation and information literacy self-efficacy: The importance of a simple desire to know. Library \& Information Science Research, vol.38, no.1, pp. 2-9, 2016.

[16] Mega, C., Ronconi, L., \& De Beni, R. What makes a good student? How emotions, self-regulated learning, and motivation contribute to academic achievement. Journal of Educational Psychology, vol.106, no.1, pp. 121-131, 2014.

[17] Wang, C.H., Shannon, D.M., \& Ross, M.E. Students’ characteristics, self-regulated learning, technology self-efficacy, and course outcomes in online learning. Distance Education, vol.34, no3, pp. 302-323, 2013.

[18] Fernandez-Rio, J., Cecchini, J.A., Méndez-Gimenez, A., Mendez-Alonso, D., \& Prieto, J.A. Self-regulation, cooperative learning, and academic self-efficacy: Interactions to prevent school failure. Frontiers in Psychology, vol.8, no.22, pp. 1-10, 2017. 